\title{
Eight Investments That Work for Physical Activity
}

\author{
Karen Milton, Nick Cavill, Anna Chalkley, Charlie Foster, Sjaan Gomersall, Maria Hagstromer, \\ Paul Kelly, Tracy Kolbe-Alexander, Jacqueline Mair, Matthew McLaughlin, James Nobles, \\ Lindsey Reece, Trevor Shilton, Ben J. Smith, and Jasper Schipperijn
}

\begin{abstract}
Background: The International Society for Physical Activity and Health (ISPAH) is a leading global organization working to advance research, policy, and practice to promote physical activity. Given the expanding evidence base on interventions to promote physical activity, it was timely to review and update a major ISPAH advocacy document-Investments that Work for Physical Activity (2011). Methods: Eight investment areas were agreed upon through consensus. Literature reviews were conducted to identify key evidence relevant to policymakers in each sector or setting. Results: The 8 investment areas were as follows: whole-of-school programs; active transport; active urban design; health care; public education; sport and recreation; workplaces; and community-wide programs. Evidence suggests that the largest population health benefit will be achieved by combining these investments and implementing a systems-based approach. Conclusions: Establishing consensus on "what works' to change physical activity behavior is a cornerstone of successful advocacy, as is having appropriate resources to communicate key messages to a wide range of stakeholders. ISPAH has created a range of resources related to the new investments described in this paper. These resources are available in the 'advocacy toolkit' on the ISPAH website (www.ispah. org/resources).
\end{abstract}

Keywords: public health, health promotion, interventions, policy, public health practice

The World Health Organization (WHO) recently published global guidelines on physical activity and sedentary behavior. ${ }^{1,2}$ These guidelines acknowledge and endorse the many benefits of physical activity to individual health and well-being, including a reduced risk of noncommunicable diseases, as well as improved mental health, sleep, and cognitive function. ${ }^{1,2}$ In addition, improvements made to population levels of physical activity can

Milton is with the Norwich Medical School, University of East Anglia, Norwich, United Kingdom. Cavill and Foster are with the School for Policy Studies, University of Bristol, Bristol, United Kingdom. Chalkley is with the National Centre of Sport and Exercise Medicine, School of Sport, Exercise and Health Sciences, Loughborough University, Loughborough, United Kingdom. Gomersall is with the School of Health and Rehabilitation Sciences, The University of Queensland, Brisbane, QLD, Australia. Hagstromer is with the Division of Physiotherapy, Department of Neurobiology, Care Sciences and Society, Karolinska Institute, Huddinge, Sweden; and the Academic Primary Care Centre, Region Stockholm, Stockholm, Sweden. Kelly is with the Physical Activity for Health Research Centre, The University of Edinburgh, Edinburgh, United Kingdom. Kolbe-Alexander is with the School of Health and Wellbeing, University of Southern Queensland, Ipswich, QLD, Australia; the School of Human Movement and Nutrition Sciences, The University of Queensland, Brisbane, QLD, Australia; and the Division of Exercise Science and Sports Medicine, Department of Human Biology, University of Cape Town, Cape Town, South Africa. Mair is with Future Health Technologies, Singapore-ETH Centre, Campus for Research Excellence And Technological Enterprise (CREATE), Singapore. McLaughlin is with the School of Medicine and Public Health, The University of Newcastle, Callaghan, NSW, Australia. Nobles is with Population Health Sciences, Bristol Medical School, University of Bristol, Bristol, United Kingdom. Reece is with the SPRINTER research group, Prevention Research Collaboration, School of Public Health, The University of Sydney, Camperdown, NSW, Australia. Shilton is with the National Heart Foundation of Australia, Subiaco, WA, Australia. Smith is with the Prevention Research Collaboration, School of Public Health, The University of Sydney, Camperdown, NSW, Australia. Schipperijn is with the Department of Sports Science and Clinical Biomechanics, University of Southern Denmark, Odense, Denmark. Milton (k.milton@uea.ac.uk) is corresponding author. contribute to other key international agendas, including the 2030 Agenda for Sustainable Development. ${ }^{3,4}$

Despite the substantial and wide-ranging benefits of physical activity, 1 out of 4 adults and 4 out of 5 adolescents globally are insufficiently active. ${ }^{5,6}$ Furthermore, inequities in participation exist by geography, sex, and social gradient. ${ }^{5}$ While many countries have developed policies to tackle physical inactivity, ${ }^{7}$ global prevalence has remained relatively static over the past 20 years, emphasizing the need for greater investment and cross-sectoral action. $^{5}$

In 2018, the WHO published the Global Action Plan on Physical Activity 2018-2030. ${ }^{8}$ This document set a global target for a $15 \%$ reduction in physical inactivity by 2030 . This global action plan outlines a wide range of actions across multiple sectors and settings, including schools, health care, transport, urban planning, public education, sport, communities, and workplaces. ${ }^{8}$ However, advocacy efforts will be required to engage each of these sectors and settings and encourage implementation of the actions outlined in the plan. ${ }^{9}$

The WHO Guidelines on Physical Activity and Sedentary Behaviour (2020) and the Global Action Plan on Physical Activity 2018-2030 are landmark documents which summarize the evidence and set the global direction for increasing population levels of physical activity. However, neither document was specifically created as an advocacy tool to increase engagement in the physical activity agenda or encourage increased investment and action.

The International Society for Physical Activity and Health (ISPAH) is a leading global organization working to advance research, policy, and practice to promote physical activity. One of ISPAH's goals is to lead advocacy actions to advance knowledge translation and improve policy and practice. Establishing consensus on 'what works' to change physical activity behavior is a cornerstone of successful advocacy, as is having appropriate resources to communicate key messages to a wide range of stakeholders. ${ }^{10,11}$ 
In 2010, ISPAH published The Toronto Charter for Physical Activity, which was a call to all countries to make physical activity a priority for all. ${ }^{12}$ Subsequently ISPAH published Noncommunicable Disease Prevention: Investments that Work for Physical Activity, ${ }^{13}$ which provided a summary of the evidence on how to get populations more active across multiple sectors and settings. Successive global policy documents, particularly the WHO Global Action Plan on Physical Activity 2018-2030, have largely aligned with the actions recommended in ISPAH's 2011 Investments That Work document; however, they include an additional key settingworkplaces.

Given the expanding evidence on the effectiveness of interventions used to promote physical activity and the inclusion of workplaces in the WHO Global Action Plan on Physical Activity 2018-2030, it was timely to review and update the 2011 Investments That Work document. The updated 2020 document includes 8 investments. ${ }^{14}$ In this paper, we briefly introduce each investment area and reflect on how the updated document can be used to develop and support a clear physical activity advocacy strategy.

\section{Methods}

The 8 areas included in the updated document were agreed upon via consensus of the ISPAH board and were based on the 2011 Investments That Work document as well as a review of the actions set out in the WHO Global Action Plan on Physical Activity 20182030. A lead for each area was appointed, who then conducted a nonsystematic literature review. Collaborations were formed between board members and experts outside of the board to draft each investment. All of the board members that contributed to the document reviewed every investment area. The final content for each of the investments was agreed upon through consensus. The 8 investments are explained below and summarized in Figure 1.

\section{Eight Investments That Work for Physical Activity}

\section{1. 'Whole-of-School' Programs}

A whole-of-school approach is a multi-component approach committed to promoting physical activity to all members of the school community through supportive policies, environments, and sustainable opportunities. There is growing evidence to support the efficacy of a range of physical activity promotion strategies in schools, including physical education programs that develop confidence, competence, and motivation to be active; ${ }^{15}$ active classrooms $;{ }^{16,17}$ after school physical activity opportunities; ${ }^{18}$ activities during recess/break times; ${ }^{19}$ and the promotion of active transport to and from school. ${ }^{20}$

\section{Active Transport}

Active transportation to and from places is a practical and sustainable way to increase daily physical activity for many people. Eight interventions have been identified that, when combined, have been shown to encourage walking, cycling, and public transport use, while reducing private motor vehicle use. These 8 interventions include improving destination accessibility; ensuring equitable distribution of employment across cities; managing demand by reducing availability and increasing the cost of parking; designing pedestrian-friendly and cycling-friendly infrastructure to support movement networks; achieving optimum levels of residential density; reducing distance to public transport; increasing the diversity of residential areas; and enhancing the desirability of active travel modes. ${ }^{21}$

\section{Active Urban Design}

The way urban and suburban environments are built and designed influences many of our conscious and unconscious behavioral choices. Research from cities globally has shown that adults who live in the most activity-friendly neighborhoods engage in at least an hour (up to an hour and a half) more physical activity per week than those living in the least activity-friendly neighborhoods. ${ }^{22}$ The creation of neighborhoods that locate shops, schools, parks, recreational facilities, jobs, and other services near homes, and provide highly connected street networks that make it easy for people to walk and cycle to destinations, have been shown to increase physical activity while simultaneously providing many additional health and environmental benefits. ${ }^{23}$

\section{Health Care}

Health care professionals come into contact with large proportions of the population and are a trusted source of health advice; therefore, they have a key role to play in promoting physical activity to their patients. Evidence indicates that primary care-based interventions that target physical activity alone, or in combination with interventions for other modifiable risk factors such as tobacco use, the harmful use of alcohol, and unhealthy diets, have shown they are effective ${ }^{24-26}$ and most are also cost-effective. ${ }^{27}$ There is strong evidence for providing brief advice and counseling, particularly when linked with community opportunities and support. ${ }^{25,28,29}$

\section{Public Education, Including Mass Media}

Public education, including mass media, can involve print, audio and electronic media, digital and social media, outdoor billboards and posters, public relations, and point of decision prompts. It can increase knowledge, awareness, and intent to increase physical activity. ${ }^{30,31}$ National and community-based communication campaigns should follow best practice principles, including positive framing, tailoring and targeting, and the use of theory and formative research. ${ }^{32}$ Public education should be combined with supportive infrastructure and other opportunities for physical activity, including community-based programs..$^{8,33}$

\section{Sport and Recreation for All}

There is increasing evidence of the wide-ranging health, social and economic benefits of sport, ${ }^{34}$ and for many, playing and engaging in sport holds significant cultural meaning. ${ }^{35}$ Participation in sport and recreation can be encouraged through the provision of accessible and appropriate places and spaces, including both indoor and outdoor facilities and amenities, ${ }^{36}$ as well as opportunities through formal and informal clubs and programs. ${ }^{37,38}$ Mass events that engage whole communities can help to create a social norm for participation in sport and recreation. ${ }^{39,40}$

\section{Workplaces}

The workplace is one of the most opportune settings for health promotion, which can benefit employers via reduced absenteeism ${ }^{41}$ and burnout ${ }^{42}$ among employees. Policies and programs include designing workplace environments that promote incidental physical 


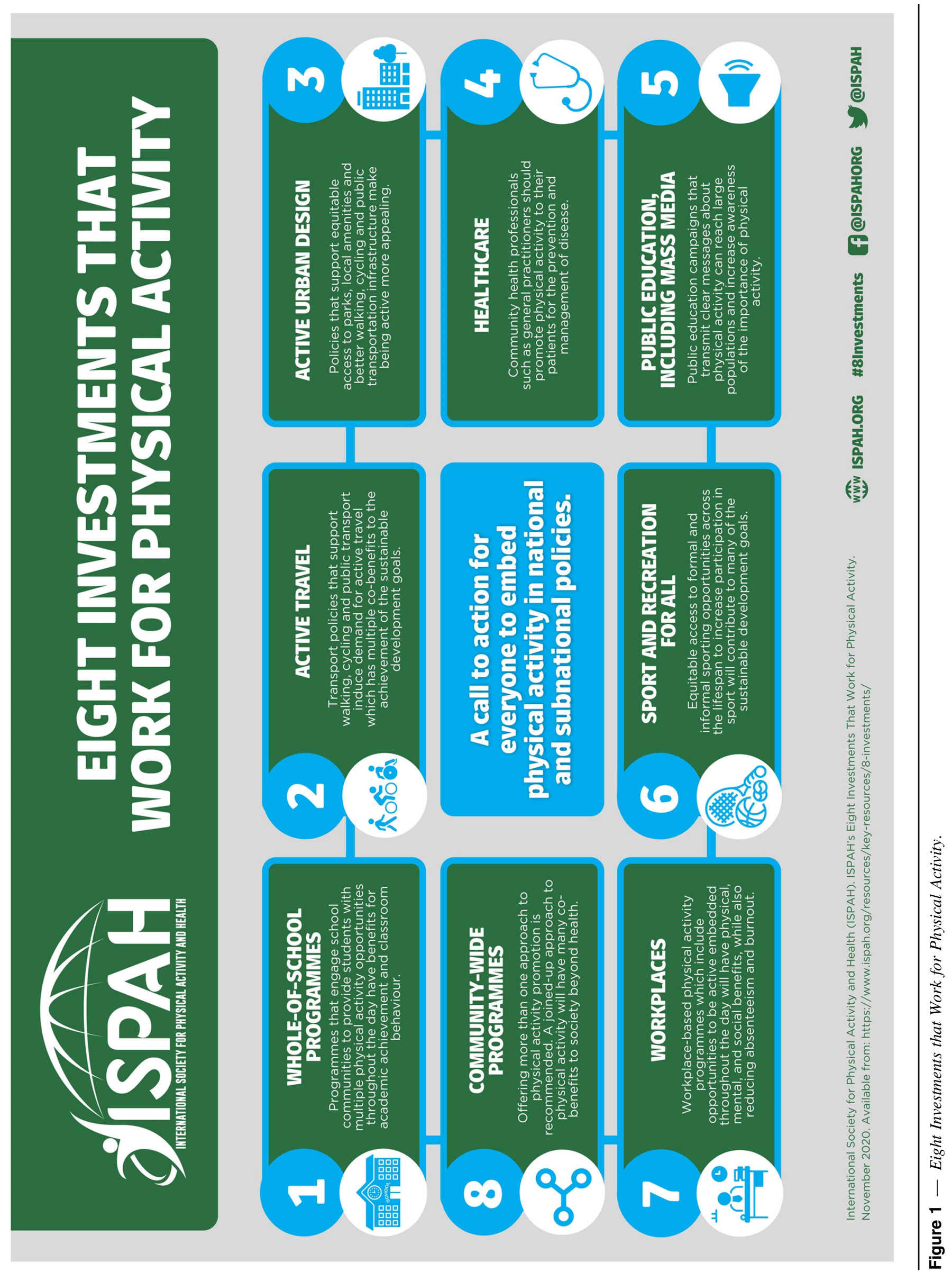


activity; supporting active commuting; educational events to inform employees of the benefits of physical activity; encouraging an active working culture (such as walking meetings); providing employees with paid time and/or flexible time for physical activity; and encouraging self-monitoring via wearable devices or mobile phone apps. $^{43,44}$

\section{Community-Wide Programs}

Community-wide programs offer more than one approach to tackle physical inactivity in a population as they operate at multiple levels (individual, social network, neighborhood, and society) to impact behavior. ${ }^{45}$ These programs can use systems-based approaches to create supportive policies, environments, and programs to encourage whole communities to be more physically active. Communitywide programs can include a mix of components identified in the preceding 7 investment areas, with emphasis on multi-component programs and a broad community reach. ${ }^{46}$ Settings such as community centers, shopping malls, senior care centers, and faith-based settings might be particularly important for an inclusive community-wide approach.

\section{Discussion}

It is well documented that physical inactivity is highly variable between countries and world regions; and there are many barriers to physical activity promotion, particularly in low and middleincome countries, which have many competing priorities. ${ }^{47}$ While ISPAH's Eight Investments That Work for Physical Activity are supported by evidence of effectiveness and have broad applicability, the feasibility of implementation will likely be context specific. For this reason, countries should begin by implementing the investments that are considered most feasible, based on factors such as political will, leadership, resources, and existing provision.

The Eight Investments That Work document is a "call to action for everyone, everywhere, including professionals, academics, civil society, and decision-makers, to embed physical activity in national and sub-national policies." ${ }^{14}$ In order to realize the greatest benefit from these investments, we encourage policymakers to adopt a systems-based approach. ${ }^{48}$ Such an approach moves away from isolated, individualized interventions to collaborative crosssector efforts that work in a complementary way to facilitate population levels of physical activity. In financially constrained times, a systems approach also helps to make efficient use of scarce resources.

Implementing a systems-based approach to physical activity promotion requires engagement with a wide range of stakeholders across multiple sectors and acknowledgment of the co-benefits of physical activity. When communicating with stakeholders, it is important to emphasize the benefits of physical activity that are likely to resonate with their current priorities. ${ }^{9,49}$ A systems-based approach allows stakeholders to identify where they fit within a bigger picture and to understand how their work contributes both to the problem and the solution. Communities also have a key role to play within a systems-based approach; they can mobilize local community assets, foster engagement from local residents, and provide insight into the reality of the problem.

In an effort to support physical activity advocacy, ISPAH has created a range of resources related to the 8 investments described in this paper. First, the Eight Investments That Work for Physical Activity document itself, which summarizes the evidence for each investment, as well as the benefits of adopting a systems-based approach. ${ }^{14}$ This document is available in the 6 official languages used by the United Nations, as well as a growing number of other languages. The authors have adapted the content of Eight Investments That Work for Physical Activity into an infographic and animation video to increase awareness of the document, distill key information for a wide range of stakeholders and reemphasize the "call to action." 50 An audiobook has been created, along with podcasts on each investment area and the importance of taking a systems-based approach. These resources form part of the 'advocacy toolkit' which is available via the ISPAH website (www.ispah.org/resources). These resources provide an entry point to conversations with stakeholders across multiple sectors and settings. It is critical that physical activity researchers, practitioners, and policymakers around the world utilize these resources to raise awareness, encourage greater engagement, and make the case for investment and action.

\section{Conclusions}

The physical activity field has advanced significantly in the decade since the Toronto Charter for Physical Activity. ${ }^{12}$ Through confident articulation and advocacy for the right combination of policies, environments, and opportunities for physical activity, we have seen these reflected in global and national policy documents. Through these policies and interventions, it is possible to create more physical activity-friendly communities and support the global population toward leading more active lifestyles. This will lead to significant gains in physical and mental health as well as other benefits, including more attractive and less polluted environments, more connected communities, improved transport systems, and a stronger economy. Given the impact of COVID-19 on population physical activity levels and mental health, there has never been a more critical time to invest in actions that work to increase population levels of physical activity.

\section{Acknowledgment}

All authors declare that they have no conflicts of interest.

\section{References}

1. World Health Organization. Guidelines on Physical Activity and Sedentary Behaviour. Geneva, Switzerland: World Health Organization; 2020.

2. Bull F, Al-Ansari SS, Biddle S, et al. World Health Organization 2020 Global Guidelines on physical activity and sedentary behaviour. $\mathrm{Br} \mathrm{J}$ Sports Med. 2020;54(24). doi:10.1136/bjsports-2020-102955.

3. United Nations. Transforming our World: The 2030 Agenda for Sustainable Development. New York, NY: United Nations; 2015.

4. International Society for Physical Activity and Health. The Bangkok Declaration on Physical Activity for Global Health and Sustainable Development. International Society for Physical Activity and Health; 2016.

5. Guthold R, Stevens GA, Riley LM, Bull FC. Worldwide trends in insufficient physical activity from 2001 to 2016: a pooled analysis of 358 population-based surveys with 1.9 million participants. Lancet Glob Health. 2018;6(10):e1077-e1086. PubMed ID: 30193830 doi: 10.1016/S2214-109X(18)30357-7

6. Guthold R, Stevens GA, Riley LM, Bull FC. Global trends in insufficient physical activity among adolescents: a pooled analysis 
of 298 population-based surveys with 1.6 million participants. Lancet Child Adolesc Health. 2020;4(1):23-35. PubMed ID: 31761562 doi:10.1016/S2352-4642(19)30323-2

7. Klepac Pogrmilovic B, Ramirez Varela A, Pratt M, Milton K, Bauman A, Biddle SJH. Pedisic Z. Availability, comprehensiveness, implementation and effectiveness of national physical activity and sedentary behaviour policies in 76 countries. Int J Behav Nutr Phys. 2020;17:116. doi:10.1186/s12966-020-01022-6

8. World Health Organization. Global Action Plan on Physical Activity 2018-2030: More Active People for a Healthier World. Geneva, Switzerland: World Health Organization; 2018.

9. Milton K, Bauman A, Faulkner G, et al. Maximising the impact of global and national physical activity guidelines-the critical role of communication strategies. Br J Sports Med. 2020;54(24):1463-1467. doi:10.1136/bjsports-2020-102324

10. Shilton T. Creating and making the case: global advocacy for physical activity. J Phys Act Health. 2008;5(6):765-776. PubMed ID: 19164814 doi:10.1123/jpah.5.6.765

11. Blanchard C, Shilton T, Bull F. Global advocacy for physical activity (GAPA): global leadership towards a raised profile. Glob Health Promot. 2014;20(4):2013.

12. International Society for Physical Activity and Health. The Toronto Charter for Physical Activity: A Global Call for Action. International Society for Physical Activity and Health; 2010.

13. International Society for Physical Activity and Health. Investments that work for physical activity. International Society for Physical Activity and Health; 2011.

14. International Society for Physical Activity and Health. ISPAH's Eight Investments that Work for Physical Activity. International Society for Physical Activity and Health; 2020.

15. Lonsdale C, Rosenkranz RR, Peralta LR, Bennie A, Fahey P, Lubans DR. A systematic review and meta-analysis of interventions designed to increase moderate-to-vigorous physical activity in school physical education lessons. Prev Med. 2013;56(2):152-161. PubMed ID: 23246641 doi:10.1016/j.ypmed.2012.12.004

16. Norris E, Steen TV, Direito A, Stamatakis E. Physically active lessons in schools and their impact on physical activity, educational, health and cognition outcomes: a systematic review and meta-analysis. Br J Sports Med. 2020;54(14):826-838. doi:10.1136/bjsports2018-100502

17. Seljebotn PH, Skage I, Riskedal A, Olsen M, Kvalø SE, Dyrstad SM. Physically active academic lessons and effect on physical activity and aerobic fitness. the Active School study: a cluster randomized controlled trial. Prev Med Reports. 2019;13:183-188. doi:10.1016/j. pmedr.2018.12.009.

18. Mears R, Jago R. Effectiveness of after-school interventions at increasing moderate-to-vigorous physical activity levels in 5- to 18-year olds: a systematic review and meta-analysis. $\mathrm{Br} \mathrm{J}$ Sports Med. 2016;50(21):1315-1324. doi:10.1136/bjsports-2015094976

19. Erwin HE, Ickes M, Ahn S, Fedewa A. Impact of recess interventions on children's physical activity-a meta-analysis. Am J Heal Promot. 2014;28(3):159-167. doi:10.4278/ajhp.120926-LIT-470.

20. Haapala HL, Hirvensalo MH, Laine K, et al. Adolescents' physical activity at recess and actions to promote a physically active school day in four Finnish schools. Health Educ Res. 2014;29(5):840-852. PubMed ID: 24906635 doi:10.1093/her/cyu030

21. Giles-Corti B, Vernez-Moudon A, Reis R, et al. City planning and population health: a global challenge. Lancet. 2016;388(10062): 2912-2924. PubMed ID: 27671668 doi:10.1016/S0140-6736(16) 30066-6
22. Sallis JF, Cerin E, Conway TL, et al. Urban environments in 14 cities worldwide are related to physical activity. Lancet. 2016;387(10034): 2207-2217. doi:10.1016/S0140-6736(15)01284-2

23. Sallis JF, Bull F, Burdett R, et al. Use of science to guide city planning policy and practice: how to achieve healthy and sustainable future cities. Lancet. 2016;388(10062):2936-2947. PubMed ID: 27671670 doi:10.1016/S0140-6736(16)30068-X

24. Vuori IM, Lavie CJ, Blair SN. Physical activity promotion in the health care system. Mayo Clin Proc. 2013;88(12):1446-1461. PubMed ID: 24290119 doi:10.1016/j.mayocp.2013.08.020

25. Sanchez A, Bully P, Martinez C, Grandes G. Effectiveness of physical activity promotion interventions in primary care: a review of reviews. Prev Med. 2015;76:S56-S67. PubMed ID: 25263343 doi: 10.1016/j.ypmed.2014.09.012

26. Onerup A, Arvidsson FD, Blomqvist A, et al. Physical activity on prescription in accordance with the Swedish model increases physical activity: a systematic review. Br J Sports Med. 2019;53(6):383-388. doi:10.1136/bjsports-2018-099598

27. Zubala A, MacGillivray S, Frost H, et al. Promotion of physical activity interventions for community dwelling older adults: a systematic review of reviews. PLoS One. 2017;12(7):e0180902. PubMed ID: 28700754 doi:10.1371/journal.pone.0180902

28. Lamming L, Pears S, Mason D, et al. What do we know about brief interventions for physical activity that could be delivered in primary care consultations? A systematic review of reviews. Prev Med. 2017;99: 152-163. PubMed ID: 28232098 doi:10.1016/j.ypmed.2017.02.017

29. Orrow G, Kinmonth AL, Sanderson S, Sutton S. Effectiveness of physical activity promotion based in primary care: systematic review and meta-analysis of randomised controlled trials. BMJ. 2012; 344(7850):16. doi:10.1136/bmj.e1389

30. Bauman A, Smith BJ, Maibach EW, Reger-Nash R. Evaluation of mass media campaigns for physical activity. Eval Progr Plan. 2006; 29(3):312-322. doi:10.1016/j.evalprogplan.2005.12.004

31. Gordon R, McDermott L, Stead M, Angus K, Hastings G. A Review of the Effectiveness of Social Marketing Physical Activity Interventions. Sterling, UK: National Social Marketing Centre; 2006.

32. Williamson C, Baker G, Mutrie N, Niven A, Kelly P. Get the message? a scoping review of physical activity messaging. Int J Behav Nutr Phys Act. 2020;17(1):1-5. doi:10.1186/s12966-020-00954-3

33. Grunseit A, Bellew B, Goldbaum E, Gale J, Bauman A. Mass Media Campaigns Addressing Physical Activity, Nutrition and Obesity in Australia: An Updated Narrative Review. Sydney, Australia: The Australian Prevention Partnership Centre; 2016.

34. UNESCO. 'Kazan Action Plan'. Paper presented at: Outcome Document of the Sixth International Conference of Ministers and Senior Officials Responsible for Physical Education and Sport (MINEPS VI), Kazan, July 13-15, 2017.

35. Hulteen RM, Smith JJ, Morgan PJ, et al. Global participation in sport and leisure-time physical activities: a systematic review and metaanalysis. Prev Med. 2017;95:14-25. PubMed ID: 27939265 doi:10. 1016/j.ypmed.2016.11.027

36. Hanlon C, Jenkin C, Craike M. Associations between environmental attributes of facilities and female participation in sport: a systematic review. Manag Sport Leis. 2019;24(5):294-306. doi:10.1080/ 23750472.2019.1641138

37. Ooms L, Veenhof C, Schipper-van Veldhoven N, de Bakker DH. Sporting programs for inactive population groups: factors influencing implementation in the organized sports setting. BMC Sports Sci Med Rehabil. 2015;7(1):12. doi:10.1186/s13102-015-0007-8

38. Eime RM, Harvey JT, Brown WJ, Payne WR. Does sports club participation contribute to health-related quality of life. Med Sci 
Sports Exerc. 2010;42(5):1022-1028. PubMed ID: 19996991 doi:10. 1249/MSS.0b013e3181c3adaa

39. Stevinson C, Hickson M. Exploring the public health potential of a mass community participation event. J Public Health. 2014;36(2): 268-274. doi:10.1093/pubmed/fdt082

40. Chalip L, Green BC, Taks M, Misener L. Creating sport participation from sport events: making it happen. Int J Sport Policy. 2017;9(2): 257-276. doi:10.1080/19406940.2016.1257496

41. Lopez BR, Casajus MJA, Garatachea VN. Physical activity as a tool to reduce disease-related work absenteeism in sedentary employees: a systematic review. Rev Esp Salud Publica. 2018;92:e:201810071.

42. Naczenski LM, Vries JD, Hooff M, Kompier MAJ. Systematic review of the association between physical activity and burnout. $J$ Occup Health. 2017;59(6):477-494. PubMed ID: 28993574 doi:10.1539/ joh.17-0050-RA

43. Plotnikoff R, Morgan P, Gilson N, Kennedy S. Action area 2: workplaces. In: Blueprint for an Active Australia. 3rd ed. Melbourne, Australia: The Heart Foundation; 2019.

44. Whitsel LP, Pate RR, Ablah E, et al. Editor's desk: promoting physical activity in the workplace. Am J Health Promot. 2019;33(2): 312-326. PubMed ID: 30739466
45. Spence JC, Lee RE. Toward a comprehensive model of physical activity. Psychol Sport Exerc. 2003;4(1):7-24. doi:10.1016/S14690292(02)00014-6

46. Baker PRA, Francis DP, Soares J, Weightman AL, Foster C. Community wide interventions for increasing physical activity. Cochrane Database Syst Rev. 2015;1.

47. Lambert EV, Kolbe-Alexander T, Adlakha D, et al. Making the case for 'physical activity security': the 2020 WHO guidelines on physical activity and sedentary behaviour from a Global South perspective. Br J Sports Med. 2020;54(24):1447-1448. PubMed ID: 33239348 doi:10.1136/bjsports-2020-103524

48. Rutter H, Cavill N, Bauman A, Bull F. Systems approaches to global and national physical activity plans. Bull World Health Organ. 2019; 97(2):162-165. doi:10.2471/BLT.18.220533

49. Bourne L. Targeted communication: the key to effective stakeholder engagement. Procedia Soc Behav Sci. 2016;226:431-438. doi:10. 1016/j.sbspro.2016.06.208

50. International Society for Physical Activity and Health. Infographic. ISPAH's eight investments that work for physical activity: infographic, animation, and call to action. Br J Sports Med. 2021. doi: 10.1136/bjsports-2020-103635 